\section{Career choice, pathways and continuing professional development of dental nurses at one institution}

\author{
C. Durkan, ${ }^{1}$ A. Belsi, ${ }^{2}$ R. Johnson ${ }^{3}$ and J. Gallagher ${ }^{4}$
}

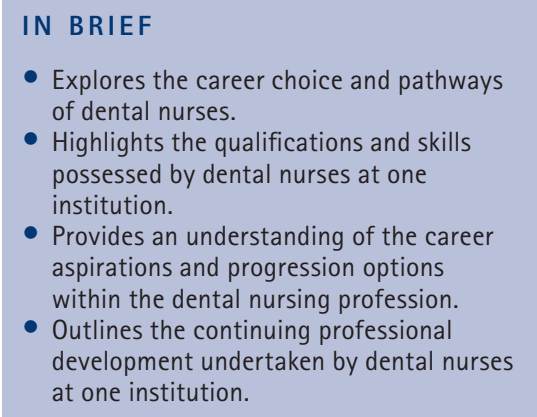

\begin{abstract}
Objective To explore the career pathways and continuing professional development of dental nurses employed at one institution relative to the scope of practice. Method A questionnaire exploring career pathways and continuing professional development of dental nurses was compiled and delivered to clinical departments. Responses were entered onto SPSS v17 for analysis. Results Ninety-eight percent $(n=64)$ of available nurses responded to the questionnaire survey. Eighty percent $(n=51)$ of the dental nurses were aged between 25 and 44 years, and 95\% $(n=61)$ were female. The ethnicity of the workforce varied; $58 \%(n=37)$ were White and this consequently constituted the largest ethnic group in the workforce. The dental nurses reported that they chose their profession for a wide variety of reasons, the most common one being the opportunity to progress in the dental sector. Before commencing training $38 \%(n=24)$ were aware of their options for progression; this increased subsequent to training with between $55 \%(n=35)$ and $66 \%(n=42)$, depending on the option, stating that they were aware of their options for progression. Eighty-three percent $(n=53)$ were trained in an additional skill and all of those who were not $(n=11)$ stated that they would like this training. Conscious sedation was the most frequently possessed additional skill and radiography was the additional skill in which the highest proportion would like to be trained. Personal satisfaction was the most significant factor affecting the willingness of the workforce to pursue career progression. Conclusion The findings suggest that amongst dental nurses employed in one institution there is evidence that the majority benefit from continuing professional development opportunities, possess additional skills and are motivated to further their skills and progress in their careers.
\end{abstract}

\section{INTRODUCTION TO THE DENTAL NURSING PROFESSION}

The role of the dental nurse is one which varies across the world, with similar roles holding different job titles such as dental auxiliary, dental assistant or dental surgery assistant. ${ }^{1}$

Dental nursing in the UK currently leads the world in becoming professionalised, requiring dental nurses to be fully trained

\footnotetext{
"Foundation Dentist, Cardiff Dental Hospital, Heath Park, Cardiff, CF14 4XY; ${ }^{2}$ Research Associate, King's College London Dental Institute at Guy's, King's College and St Thomas' Hospitals; ${ }^{3}$ Head of Dental Nursing, Dental Hygiene and Therapy, and Allied Health Professionals, Guy's and St. Thomas' Hospital Trust: ${ }^{4}$ King's College London Dental Institute at Guy's, King's College and St Thomas' Hospitals and Head of Oral Health Services Research \&t Dental Public Health, Caldecot Road, Denmark Hill, London, SE5 9RW

${ }^{*}$ Correspondence to: Mr Colum Durkan

Email:columdurkan@yahoo.co.uk
}

\section{Online article number E1}

Refereed Paper - accepted 14 May 2012

DOI: 10.1038/sj.bdj.2012.663

${ }^{\circledR}$ British Dental Journal 2012; 213: E1 and registered with the GDC, an important step in its development building on past reviews such as that conducted by Nuffield. ${ }^{2}$ The core and additional skills of a dental nurse in the United Kingdom are outlined in the Scope of practice published by the General Dental Council. ${ }^{3}$ Although there are certain core duties which all registered dental nurses undertake, there are many additional skills which may be developed in the course of their careers. ${ }^{3}$ The scope of practice of a dental nurse is likely to change over the course of their career; expanded by the acquisition of new skills, or narrowed by the deepening of knowledge, thus resulting in "career enhancement: ${ }^{4}$

From 1 August 2008, it became mandatory for all dental nurses working in the UK to register with the General Dental Council. Student dental nurses on an accredited training course are not required to register until after qualification. On 31 December 2010, there were 44,147 dental nurses registered, 208 of which were not resident in the $\mathrm{UK}^{5}$

Dental nurses in training study for a qualification such as the National Certificate, NVQ level 3 in Dental Nursing, or the Certificate of Higher Education in Dental Nursing, all of which are recognised by the General Dental Council. Most dental nurses commence their training and professional career in general practice and study in the evenings or on day release, although some begin in dental hospitals and in the community dental service. No specific academic qualifications are required to train as a dental nurse. However, further training is essential to progress and experience of working as a dental nurse is usually a requirement for those wishing to become a dental hygienist or therapist. General nursing, in comparison, requires the individual to hold a degree or diploma in nursing, ${ }^{6}$ although from September 2013 all new entrants will have to follow a degree programme. ${ }^{7}$ 
Continuing professional development (CPD) for dental nurses in the UK has been set by the General Dental Council at a minimum of 150 hours per 5-year CPD cycle, of which 50 hours must be classified as verifiable. ${ }^{8}$

\section{METHOD}

The approval of the institution's clinical governance committee was gained for this staff survey project. The questionnaire was devised using previous work in the dental workforce field ${ }^{9-11}$ and professional policy. ${ }^{3}$ A pilot enabled the questions to be tested and then amended to include the hospital certificate as a qualification; it was completed by dental nurses not participating in the final questionnaire due to planned leave. The final questionnaire was carried out over one day and had four sections: qualifications, career choice, current role and career expectations, and demographic questions.

\section{RESULTS}

Sixty-four of the 65 available dental nurses completed the questionnaire, giving a response rate of $98 \%$. The total dental nursing workforce employed at Guy's and St. Thomas' Hospital Trust on the day was 116, 65 of whom were working on the day of the audit. Ninety-five percent of the respondents were female and 5\% male. Eighty percent $(n=51)$ of the dental nurses were aged between 25 and 44 years, and 95\% $(n=61)$ were female (Fig. 1). The ethnicity of the dental nursing workforce is displayed in Figure 2, with the categories grouped based on the current Office of National Statistics classification.

The current roles of the dental nurse respondents are outlined in Figure 3, with dental staff nurse being the most common $(64 \% ; n=41)$. The roles are comparable with similar institutions in the sector, where a dental staff nurse is a qualified, career grade dental nurse with a primarily chairside role.

As qualified dental nurses, all respondents had at least one dental nursing qualification, almost one third of respondents $(31 \% ; n=20)$ had two or more and $5 \%$ $(\mathrm{n}=3)$ had three. The percentage of dental nurses holding each qualification can be seen in Figure 4. All 97\% of respondents $(n=62)$ who indicated where they qualified had qualified in the UK. The

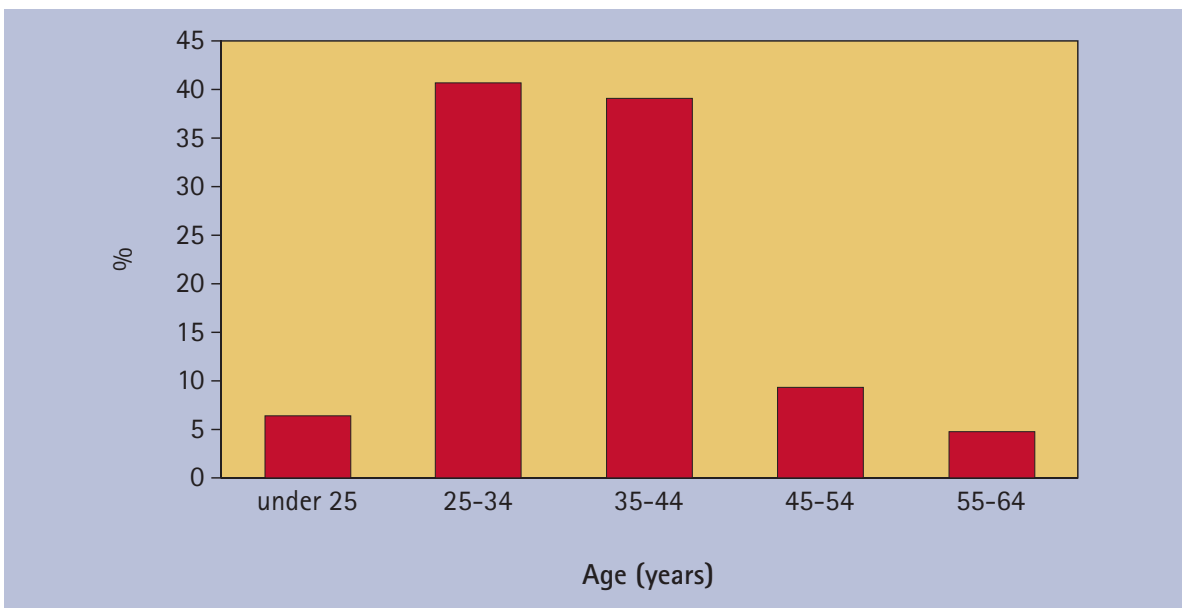

Fig. 1 Age of dental nurse respondents $(n=64)$

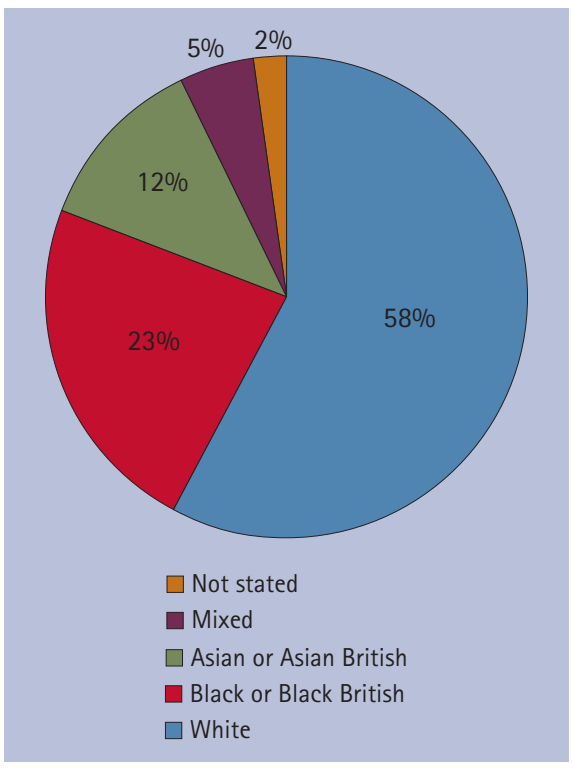

Fig. 2 Ethnicity of dental nurse respondents $(n=64)$. NB: there were no respondents who selected 'Chinese or other ethnic group'

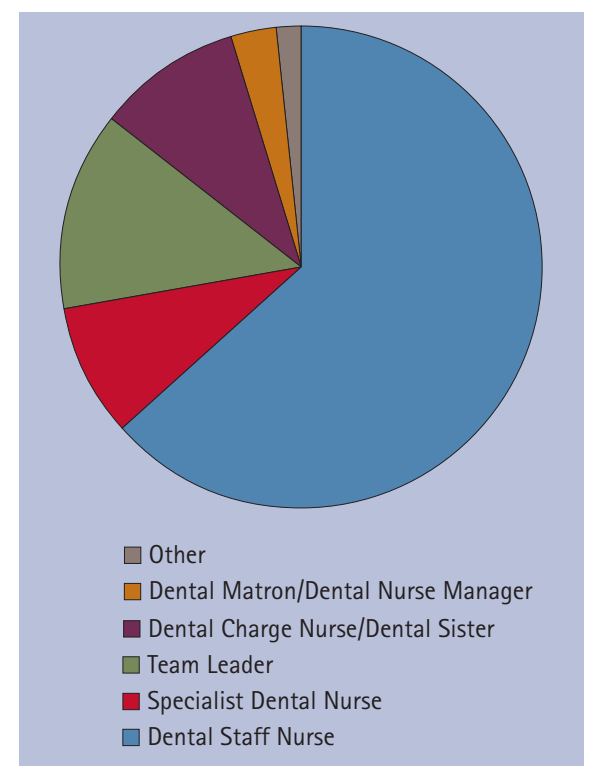

Fig. 3 Current role of dental nurse respondents $(n=64)$. NB: the 'other' was not specified

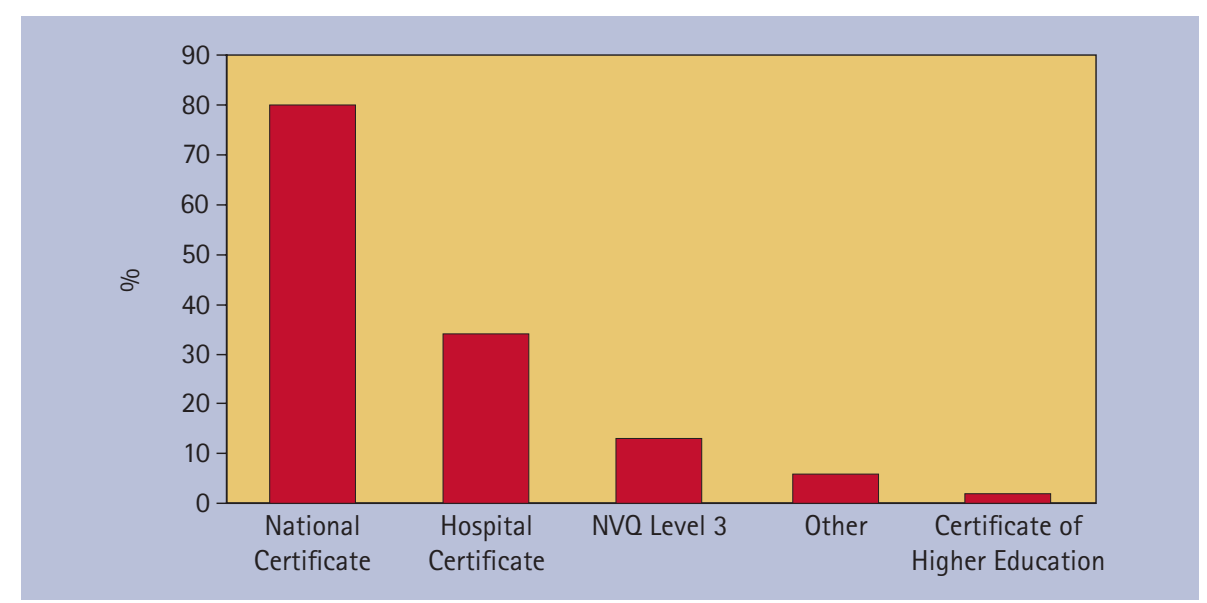

Fig. 4 Dental nursing qualifications held by dental nurse respondents $(n=64)$. NB: there were no respondents who selected 'VRO level 3'

years in which they qualified have been grouped and are shown in Figure 5. The mode was 2001-2005, with there being fewer more recently qualified respondents.
The average length of time the respondents had been practising as dental nurses was 13.9 years, including their training period. 
The general qualifications held by the dental nursing workforce were varied with $64 \%$ qualified to GCSE level or equivalent and $8 \%$ in possession of a degree. This can be seen in Figure 6. Sixteen percent had other qualifications separate from those available for selection; these ranged in subject but typically lay in the dental field such as dental technology, oral health education and sedation and special care nursing.

The factors influencing the career choice of the respondents were varied (Fig. 7) and although the opportunity was provided for other influencing factors to be specified, none were. 'Opportunity to progress in dental sector' was the most popular response, followed by 'preference for healthcare' and 'job availability'. Multiple responses were common. Sixteen (25\%) indicated one influencing factor; $48(75 \%)$ indicated two or more; $39(61 \%)$ indicated three or more and 22 (34\%) indicated four or more influencing factors. Half of the respondents $(n=32)$ stated that they considered general nursing as an alternative career.

Those who considered general nursing as a career and gave reasons for subsequently pursuing a career in dental nursing were typically restricted by their qualifications, personal commitments and the nature of the training. Some elaborated by explaining that children and family life made the shift work required in general nursing impractical, or that dental nursing was an easier course and it was a quicker way to gain a qualification. Many responses had a financial theme with the unavailability of salaried training for general nurses preventing them from entering the profession. There were also some respondents who claimed an interest in dentistry was what attracted them to the profession as opposed to general nursing; however, only $42 \%$ ( $n=27$ ) engaged in work shadowing prior to commencing their training as a dental nurse.

The respondents' awareness of options for career progression prior to commencing their training is presented in Figure 8. Interestingly, despite 'opportunity to progress in dental sector' being the most popular career influencing factor (Fig. 7), only $38 \%(n=24)$ were aware of what their options were and 33\% ( $\mathrm{n}=21)$ were unaware options for progression within the

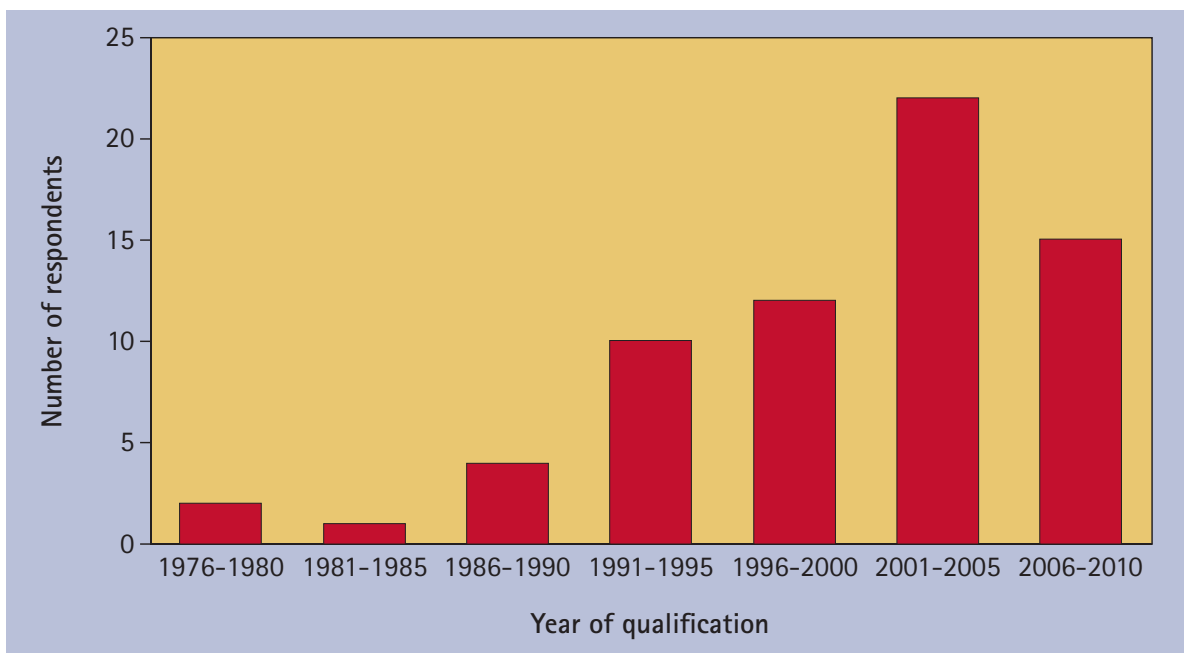

Fig. 5 Year of qualification of dental nurse respondents $(n=61)$. NB: there were three respondents who did not indicate the year in which they qualified

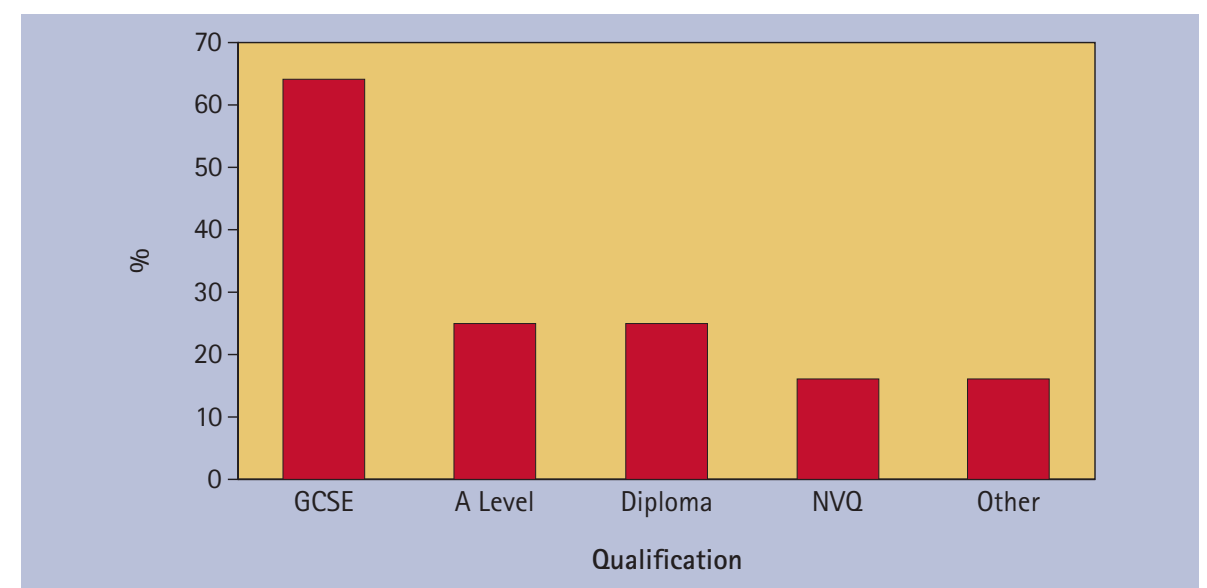

Fig. 6 Educational qualifications held by dental nurse respondents $(n=64)$. NB: the specified categories include equivalent qualifications

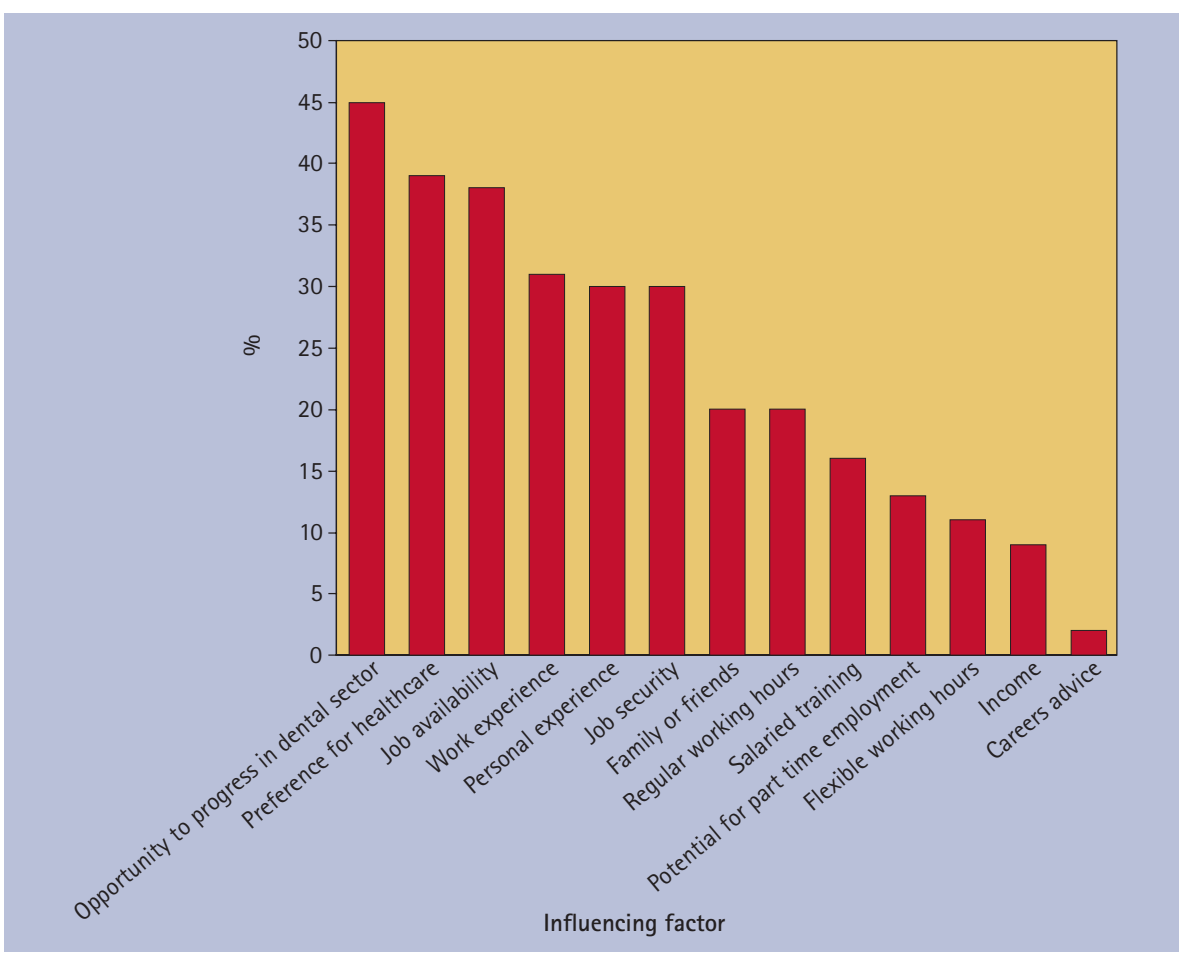

Fig. 7 Influencing factors on career choice of dental nursing $(n=62)$. NB: multiple responses were typical. Although the option was given to specify another factor, no respondents did so 
dental sector existed prior to commencing their training.

All $(n=64)$ of the respondents were using their dental nursing qualification in a dental hospital at the time of the audit (Fig. 9). Seventy-three percent $(n=47)$ had used their qualification in two or more settings, while 18\% $(\mathrm{n}=12)$ had used their qualification in three or more places.

The present training status of the workforce with respect to their acquisition and use of additional skills was summarised. There were several notable findings as presented in Table 1:

- Conscious sedation was the additional skill acquired by the largest proportion of the surveyed workforce; of the 21 respondents who stated they had been trained in it, 18 (86\%) had used it

- Impression taking was the additional skill in which the highest number of the surveyed workforce had been trained, but never used; 41\% of respondents were trained in impression taking, but only 16\% had used the skill. The trend was similar for suture removal, with 35\% of the workforce trained in it, but only 13\% having used the skill

- Removable appliance repair was the additional skill which the fewest members of the surveyed workforce used; just one respondent indicated that they had used it, although a total of four were trained in it.

Looking to the future:

- Eighty-three percent of respondents ( $n=53$ ) stated that they were trained in an additional skill, while 83\% ( $n=53)$ stated that they would like training in one or more skills. Of those who were not trained in an additional skill $(\mathrm{n}=11)$, all stated that they would like training

- Radiography was the additional skill in which the highest proportion of the surveyed workforce would like to be trained, with $41 \%$ expressing this interest. Twentyfour percent were already trained in radiography, 79\% of whom had used their training

- There was least demand for training in the placement of rubber dam. Just 3 of the 13 dental nurses already trained in this had used the skill.

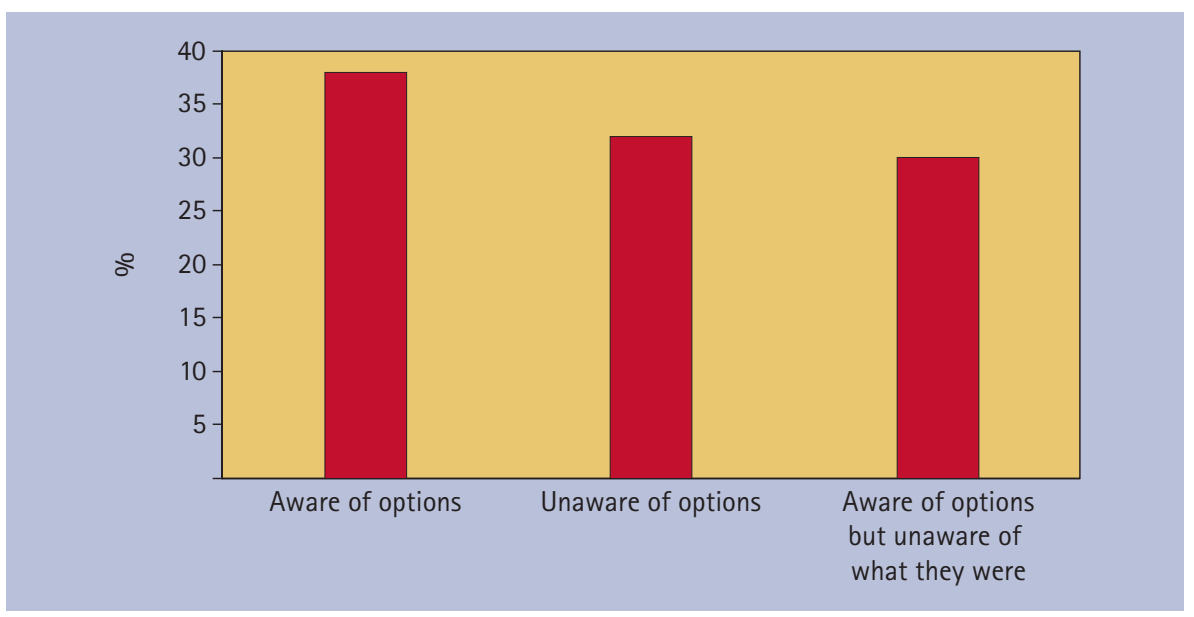

Fig. 8 Awareness of options for career progression prior to commencing training $(n=64)$

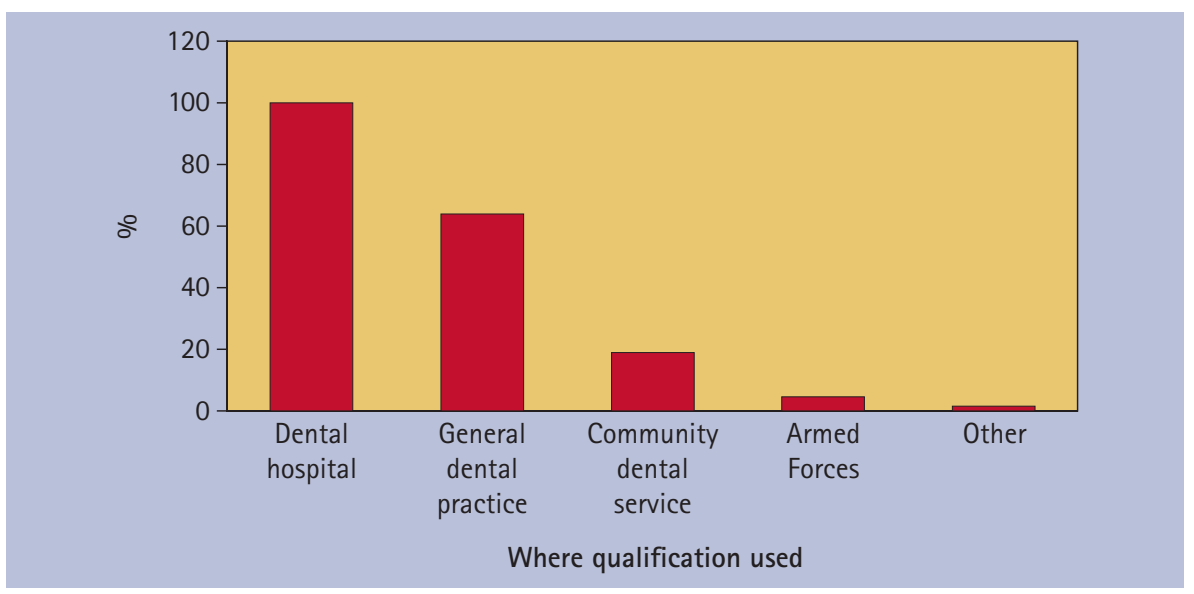

Fig. 9 Where dental nursing qualification has been used $(n=64)$

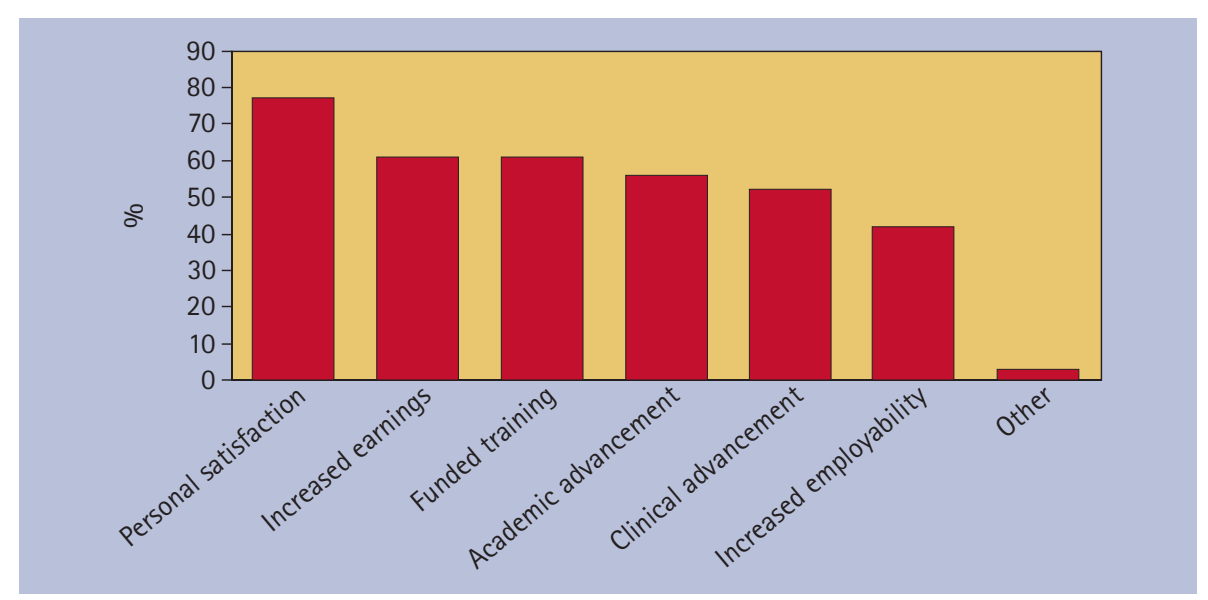

Fig. 10 Factors affecting willingness to pursue career progression $(n=64)$

Many respondents gave reasons for wanting to extend their scope of practice; common themes were associated with 'adding variety to their role', 'being able to deliver better service' to their teams and patients, 'being more valued by their colleagues', 'career progression', an 'enjoyment of learning', an 'interest in the courses' and 'the potential to teach others'. It should be noted that at the time of the audit the service offering at the surveyed institution was varied and stable, which is likely to have influenced the training requirements of the dental nursing workforce there. The dental nursing workforce at an institution with a less varied or evolving service offering is likely to have different training requirements to reflect this.

Awareness of the different options for career progression was variable and not universal (Fig. 8). There was least awareness of the option to become a specialist 


\begin{tabular}{|c|c|c|c|c|c|c|c|c|}
\hline \multirow{2}{*}{ Skill } & \multicolumn{2}{|c|}{$\begin{array}{l}\text { I am trained in this } \\
\text { but have never used it }\end{array}$} & \multicolumn{2}{|c|}{$\begin{array}{l}\text { I am trained in this } \\
\text { and have used it }\end{array}$} & \multicolumn{2}{|c|}{$\begin{array}{l}\text { I would like to be } \\
\text { trained in this }\end{array}$} & \multicolumn{2}{|c|}{ No response } \\
\hline & Frequency & $\%$ & Frequency & $\%$ & Frequency & $\%$ & Frequency & $\%$ \\
\hline Oral health education and promotion & 6 & 9 & 9 & 14 & 23 & 36 & 26 & 41 \\
\hline Conscious sedation & 3 & 5 & 18 & 28 & 19 & 30 & 24 & 38 \\
\hline Special needs dentistry & 2 & 3 & 8 & 13 & 21 & 33 & 33 & 52 \\
\hline Intraoral photography & 9 & 14 & 8 & 13 & 23 & 36 & 24 & 38 \\
\hline Shade taking & 2 & 3 & 9 & 14 & 17 & 27 & 36 & 56 \\
\hline Placing rubber dam & 10 & 16 & 3 & 5 & 16 & 25 & 35 & 55 \\
\hline Measuring and recording plaque indices & 4 & 6 & 6 & 9 & 22 & 34 & 32 & 50 \\
\hline Casting and trimming study models & 8 & 13 & 5 & 8 & 21 & 33 & 30 & 47 \\
\hline Suture removal & 14 & 22 & 8 & 13 & 23 & 36 & 19 & 30 \\
\hline Applying fluoride varnish & 5 & 8 & 3 & 5 & 23 & 36 & 19 & 30 \\
\hline Constructing wax rims and special trays & 4 & 6 & 2 & 3 & 22 & 34 & 36 & 56 \\
\hline Removable appliance repair & 3 & 5 & 1 & 2 & 18 & 28 & 42 & 66 \\
\hline Cephalograph tracing & 3 & 5 & 2 & 3 & 16 & 25 & 43 & 67 \\
\hline Radiography & 3 & 5 & 12 & 19 & 26 & 41 & 23 & 36 \\
\hline Topical anaesthetic application & 3 & 5 & 3 & 5 & 21 & 33 & 37 & 58 \\
\hline Mouthguard and bleaching tray construction & 3 & 5 & 6 & 9 & 23 & 36 & 32 & 50 \\
\hline Vacuum formed retainer construction & 4 & 6 & 2 & 3 & 19 & 30 & 39 & 61 \\
\hline Impression taking & 16 & 25 & 10 & 16 & 24 & 38 & 14 & 22 \\
\hline
\end{tabular}

dental nurse with just 55\% ( $\mathrm{n}=35)$ indicating they were aware of this, although it was the option which the largest number of the workforce were interested in pursuing with $34 \%(\mathrm{n}=22)$ stating this. There was least interest in becoming a practice manager with just $11 \%(n=7)$ of the workforce possessing an interest in pursuing this option.

The most common factor affecting the willingness of the workforce to pursue career progression was personal satisfaction, with $77 \%(\mathrm{n}=49)$ indicating this. Increased employability was the specified factor with the smallest number of respondents; 42\% $(\mathrm{n}=27)$ stated that it affected their willingness to pursue career progression (Fig. 10). Seventy-seven percent $(n=49)$ of the workforce selected two or more influencing factors and 67\% ( $n=43$ ) selected three or more.

The number of hours of continuing professional development (CPD) gained by the workforce within the 12 months prior to conducting the survey ranged from 0 to $250(\mathrm{n}=49)$. Four respondents $(\mathrm{n}=49)$ had completed the required CPD for the 5 year cycle within the 12 month period. The average number of hours was 51.6 and the modal number of hours was 25 . Some respondents stated that they would like more CPD in certain areas; their preferences included clinical options such as decontamination, impression taking, radiography, suture removal and more detailed training in medical emergencies and nonclinical options such as complaints handling and teambuilding.

\section{DISCUSSION}

The respondents were a representative sample of the dental nursing workforce within the hospital. The findings from this group of hospital dental nurses reflect the fact that the surveyed workforce were all employed in the public sector, within an established institution; however, it was encouraging to note that the majority had worked in a range of settings at the time of the survey. There was clearly movement from other settings, primarily general dental practice, which is bound to be professionally beneficial as this enables the acquisition of a broader range of skills and experience by the workforce.

The principal reason for entering dental nursing appears to have been the potential for career progression, facilitated by salaried training. Interestingly, in a parallel manner to dental students having considered medicine, a significant proportion had considered general nursing but rejected this for job-related reasons. Others reported a specific interest in dentistry was what attracted them to the profession as opposed to general nursing; however, less than half of respondents (42\%) reported having engaged in work shadowing prior to commencing their training as a dental nurse. One important factor is the financial incentive attached to training as a dental nurse.

Dental nurses were routinely accessing continuing professional development as is necessary with professional registration. ${ }^{7}$ There was universal interest in career progression with the entirety of the surveyed workforce having either extended, 
or expressed a desire to extend, their scope of practice. Given that the dental hospital environment provides greater professional development opportunities, it is perhaps not surprising that this group have selfselected to work in this setting. Nonetheless, it highlights how these dental professionals are taking advantage of professional opportunities, which will also contribute to their professional requirements for CPD. ${ }^{8}$ More than half of respondents (83\%) were trained in an additional skill; all of those who were not, stated that they would like such training. Conscious sedation was the most frequently possessed additional skill and radiography was the additional skill in which the highest proportion wished to be trained.

Regarding career progression, there was greatest interest in the senior dental nursing roles, which are generally limited to the hospital setting. The options a dental nursing workforce are interested in pursuing may well be influenced by past or present working environments. Other options in which interest was expressed included orthodontic therapist, infection control nurse, dentist and dental radiography tutor. This suggests that it is important that opportunities are made available to facilitate professional development and career progression. These findings highlight the major developments taking place within dental nursing and should be examined in more detail across settings and promoted as reasons for considering a career in dental nursing.

\section{CONCLUSION}

The majority of the staff engage with professional development opportunities and possess additional skills. There is considerable motivation among the workforce to further their skills and progress in their careers.

The authors wish to thank the Clinical Director for supporting this project, which was conducted as a special study module to gain information on the professional development of dental nurses at Guy's and St. Thomas' Hospital Trust. Our appreciation goes to all of the dental nurses who participated by completing and returning a questionnaire.

1. Gallagher J E. Dentists. In Heggenhougen K, Quah S (eds) International encyclopaedia of public health. pp 126-136. San Diego: Academic press, 2008.
2. Nuffield Foundation. Education and training of personnel auxiliary to dentistry. London: The Nuffield Trust, 1993.

3. General Dental Council. Scope of practice. Annual report. London: General Dental Council, 2009

4. Dubois C-A, McKee M, Sibbald B. Changing professional boundaries. In Figueras J, McKee M, Mossialos E, Saltman R (eds) European observatory on health systems and policies series. pp 63-78. Maidenhead: Open University Press; 2006.

5. General Dental Council. Dental register: summary statistics provided on request. Annual report. London: General Dental Council, 2010.

6. Maynard K. Dental nurse vs. medical nurse. Vital 2007; 4: 26-28.

7. NHS Careers. Nursing. 2011. Online information available at $h t t p: / / w w w . n h s c a r e e r s . n h s . u k / n u r s-$ ing_entry.shtml (accessed June 2012).

8. General Dental Council. Continuing professional development for dental care professionals. London: General Dental Council, 2012.

9. Gallagher J E, Patel R, Donaldson N, Wilson N H F. The emerging dental workforce: why dentistry? a quantitative study of final year dental students' views on their professional career? BMC Oral Health [serial on the Internet]. 2007; 7: 7. Online article available at http://www.biomedcentral.com/14726831/7/7 (accessed June 2012)

10. Gallagher J E, Clarke W, Wilson N H. The emerging dental workforce: short-term expectations of, and influences on dental students graduating from a London dental school in 2005. Prim Dent Care 2008; 15: 93-101.

11. Gallagher J E, Patel R, Wilson N H. The emerging dental workforce: long-term career expectations and influences. A quantitative study of final year dental students' views on their long-term career from one London dental school. BMC Oral Health. 2009; 9: 35 